\section{Uncovering the Power of Personality to Shape Income}

\section{(II)}

\section{Jaap J. A. Denissen ${ }^{1}$, Wiebke Bleidorn', Marie Hennecke ${ }^{3}$, Maike Luhmann ${ }^{4}$, Ulrich Orth ${ }^{5}$, Jule Specht ${ }^{6,7}$, and Julia Zimmermann ${ }^{8}$}

${ }^{1}$ Department of Developmental Psychology, Tilburg University; ${ }^{2}$ Department of Psychology, University of California, Davis; ${ }^{3}$ Department of Psychology, University of Zurich; ${ }^{4}$ Department of Psychology, Ruhr University Bochum; ${ }^{5}$ Department of Psychology, University of Bern; ${ }^{6}$ Institut für Psychologie, Humboldt-Universität zu Berlin; ${ }^{7}$ German Institute for Economic Research (DIW Berlin), Berlin, Germany; and ${ }^{8}$ Institut für Psychologie, FernUniversität in Hagen
Psychological Science 2018, Vol. 29(1) 3-13 (C) The Author(s) 2017 (c) (i) (8)

Reprints and permissions: sagepub.com/journalsPermissions.nav DOI: $10.1177 / 0956797617724435$ www.psychologicalscience.org/PS (S)AGE

\begin{abstract}
The notion of person-environment fit implies that personal and contextual factors interact in influencing important life outcomes. Using data from 8,458 employed individuals, we examined the combined effects of individuals' actual personality traits and jobs' expert-rated personality demands on earnings. Results from a response surface analysis indicated that the fit between individuals' actual personality and the personality demands of their jobs is a predictor of income. Conclusions of this combined analysis were partly opposite to conclusions reached in previous studies using conventional regression methods. Individuals can earn additional income of more than their monthly salary per year if they hold a job that fits their personality. Thus, at least for some traits, economic success depends not only on having a "successful personality" but also, in part, on finding the best niche for one's personality. We discuss the findings with regard to labor-market policies and individuals' job-selection strategies.
\end{abstract}

\title{
Keywords
}

personality, socioeconomic status, performance, individual differences, open data, open materials

Received 2/15/17; Revision accepted 7/14/17

Personality is defined as a relatively stable pattern of thoughts, feelings, and behaviors that explains individual differences in a wide range of important life outcomes (Roberts, Kuncel, Shiner, Caspi, \& Goldberg, 2007). In recent years, psychologists and economists have increasingly recognized the importance of personality as a predictor of economic outcomes (Borghans, Duckworth, Heckman, \& ter Weel, 2008; Bowles, Gintis, \& Osborne, 2001; Groves, 2005; Judge, Higgins, Thoresen, \& Barrick, 1999; Mueller \& Plug, 2006). Empirically, however, observed associations between personality and earnings have turned out to be relatively small (Barrick \& Mount, 1991; Fletcher, 2013; Nyhus \& Pons, 2005). On the basis of a moderator analysis of effect sizes reported in the literature, which indicated that personality traits interact with job requirements in predicting job performance, Judge and Zapata (2015) recently called for researchers evaluating the effects of personality on job outcomes to consider not only the person but also the requirements of a given job. Interactions between personality and job demands are important from a theoretical perspective, in that the theory of person-environment fit (Spokane, Meir, \& Catalano, 2000) and dynamic-interactive theories of personality development (Roberts \& Robins, 2004) assume that personality traits and environmental characteristics (such as job demands) interact to predict important life outcomes in general. Moreover, establishing optimal combinations of personality traits and job demands will be informative for applied researchers who aim to optimize person-environment fit.

\section{Corresponding Author:}

Jaap J. A. Denissen, Department of Developmental Psychology, Tilburg University, Warandelaan 2, 5037 AB Tilburg, The Netherlands E-mail: jjadenissen@gmail.com 
In the current study, we investigated how characteristics of persons and their jobs interact as predictors of income. The job characteristic we focused on was the personality demands of a job, defined as the personality traits of ideal jobholders. We focused on the interaction between these demands and the actual Big Five traits of jobholders. These traits (extraversion, agreeableness, conscientiousness, emotional stability, and openness) form a comprehensive framework for describing individual differences in affect, behavior, and cognition that has been validated across cultures and related to a broad range of life outcomes (John \& Srivastava, 1999; Roberts et al., 2007). We set out to test the hypothesis that the interaction between jobholders' actual personality traits and their jobs' personality demands predicts income. Given the novel nature of our methodology, we did not have specific hypotheses regarding the exact form of this interaction.

Our study went beyond existing research in a number of ways. First, we assessed job characteristics in an objective fashion by using independent experts' ratings (see also Judge \& Zapata, 2015). Second, we assessed jobs in terms of the levels of the Big Five traits that they require for optimal performance (Barrick, Mount, \& Li, 2013). The quantification of jobs' personality demands is a novel way to operationalize relevant environmental pressures. This operationalization not only adds possible new situational dimensions to psychological research but also offers the important advantage of creating commensurate (i.e., comparable) dimensions for the measurement of actual personality and job demands (Tinsley, 2000). Having commensurate dimensions greatly facilitated the interpretation of results we obtained with response surface analysis (RSA), a technique we explain further in the Method section. Third, we used a nationally representative study that included a broad range of jobs and personality profiles, thereby ensuring a broad range of values for the personality and job variables, which was necessary to demonstrate an effect of person-job fit.

\section{Method}

\section{Sample}

Our data came from the German Socio-Economic Panel (SOEP; Wagner, Frick, \& Schupp, 2007). The SOEP sample is representative of the German population, and data collection is carried out by trained interviewers following standard protocols. For each participant, we used data collected during the year when their personality traits were first assessed. Our initial sample consisted of 18,971 individuals who were employed at the time of this assessment. Because we focused on annual income, we excluded 6,711 individuals who were not employed full-time and 1,355 individuals who had not worked without interruption for the entire past year. Furthermore, we excluded 2,447 individuals with missing or outlier data. Of these individuals, 1,264 did not have a coded job, and 1,166 lacked data on the covariates; only 17 individuals were outliers on the income variable. Following these exclusions, we had a working file of 8,458 individuals. Power analysis for RSA is not straightforward. However, given that regression coefficients serve as input, it is illustrative that (after Bonferroni correction) this sample size was sufficient to detect an $f^{2}$ of .002 , which corresponds to a very small effect. As more men than women are employed full-time in Germany, the majority of participants in our sample were men $(n=5,720,68 \%)$. The mean age of participants was 43.7 years $(S D=10.5$ years). The first personality assessment was in 2005 for 6,113 of the included participants, in 2009 for 770 of the participants, and in 2013 for 1,575 of the participants. Assessment year was not associated with differences in salary (likely because of the depressing effects of the 2008 financial crisis), so we did not control for this variable.

\section{Measures}

The mean income in our final sample was €39,060 per year, and the median income was $€ 33,180$ per year. We log-transformed income to account for the skewed nature of the distribution. We also controlled income for geography $(0=$ former West Germany, $1=$ former East Germany), gender $(0=$ men, $1=$ women $)$, age (linear and squared), years of education (linear and squared), marital status ( $0=$ married, $1=$ unmarried $)$, years of experience in the job, and work hours per week (see the Supplemental Material available online for more information). The residuals were approximately normally distributed.

Participants filled out a short German version (Gerlitz \& Schupp, 2005; Hahn, Gottschling, \& Spinath, 2012) of the Big Five Inventory (John \& Srivastava, 1999), which served as our measure of personality traits. On scales from 1 (not at all true) to 7 (applies fully), participants indicated whether they agreed with 15 selfdescriptions. Sample items include "I see myself as someone who worries a lot" (emotional stability; reverse-scored), "I see myself as someone who is reserved" (extraversion; reverse-scored), "I see myself as someone who has an active imagination" (openness to experience), "I see myself as someone who has a forgiving nature" (agreeableness), and "I see myself as someone who does things efficiently" (conscientiousness). The specific questions are available on the Web at http://zis.gesis.org/skala/Schupp-Gerlitz-Big-FiveInventory-SOEP-(BFI-S). Table 1 presents the means, 
Table 1. Means, Standard Deviations, and Reliabilities of the Ratings of Actual Personality and Job Personality Demands

\begin{tabular}{lcccc}
\hline & & & $\begin{array}{c}\text { Internal } \\
\text { consistency } \\
(\alpha)\end{array}$ & $\begin{array}{c}\text { Agreement } \\
(r)\end{array}$ \\
Measure & $M$ & $S D$ & & \\
\hline Actual personality (self-ratings) & & & .65 & - \\
$\quad$ Extraversion & 4.86 & 1.13 & .48 & - \\
Agreeableness & 5.33 & 0.98 & .58 & - \\
Conscientiousness & 6.01 & 0.84 & .60 & - \\
Emotional stability & 4.33 & 1.18 & .62 & .72 \\
Openness to experience & 4.53 & 1.16 & & .62 \\
Job-demanded personality & & & .66 & .48 \\
(expert ratings) & & & $.34^{\mathrm{a}}$ & .55 \\
$\quad$ Extraversion & 4.58 & 0.84 & .76 & .75 \\
$\quad$ Agreeableness & 4.59 & 0.52 & .69 & - \\
Conscientiousness & 5.77 & 0.33 & & - \\
$\quad$ Emotional stability & 5.63 & 0.45 & & \\
$\quad$ Openness to experience & 4.18 & 0.67 & & \\
\hline
\end{tabular}

aSubsequent analysis indicated that the low internal consistency of the experts' conscientiousness ratings was partly due to one rater having difficulty with the item "does a thorough job." Excluding this item for this particular rater increased the average internal consistency to .51 across raters.

standard deviations, and internal consistencies of the five personality scales. Reliabilities were lower than usual in some cases, which is typical for very brief personality scales (such as the one used in the SOEP) because they measure broad, multifaceted constructs with just a few items. Nevertheless, these brief scales correlate strongly with longer versions and can therefore be assumed to have adequate reliability and validity (Hahn et al., 2012).

The personality demands of participants' jobs (hereafter, job personality demands) were rated by two occupational experts of the German Federal Employment Agency, who were blind to the hypotheses. ${ }^{1}$ Both experts held a master's degree in psychology and had worked as occupational psychologists for the Federal Employment Agency for 6 years or longer. In addition to being experts with regard to occupational counseling, they were permanent members of the working team that maintained and developed a database (BERUFENET, https://berufenet.arbeitsagentur.de/) with entry requirements for specific occupations, including descriptions of occupation-specific psychological requirements. In a first session, the raters extensively discussed the rating system with another expert of the agency, who was informed about the goals of the study and the details of the rating procedure. They then jointly rated 25 test professions that were not included in the study, discussed the results, and calibrated their criteria as necessary. Next, they independently rated all of the 176 jobs held by at least 10 participants in either the 2005 or the 2009 assessment. (Jobs were rated before the data for the 2013 wave were available.) This procedure allowed the expert coders to rate the occupations of the great majority (91.3\%) of participants with maximum efficiency. Jobs were distinguished by their four-digit codes in the International Labour Organization's International Standard Classification of Occupations (Wolf, 1997). This system offers a fairly differentiated classification (e.g., cook, chemist, member of the armed forces). Using an online questionnaire, the two expert raters indicated the personality profile of the ideal candidate for each job. Specifically, the question for each job began, "Optimal performance in this profession demands a personality that is described as follows," and this opening was followed by the exact same items and rating scale used for the self-ratings of personality. This procedure produced point estimates corresponding to exact job demands (as opposed to, e.g., acceptable or desirable ranges of personality trait levels).

Interrater agreement was satisfactory, and internal consistencies across items (averaged across the two raters) were high, except for conscientiousness. The average internal consistency was lower for this scale because one of the raters had difficulty with the item "does a thorough job." Excluding this item improved the reliability to .51 . Table 1 presents the mean, standard deviation, average internal consistency, and interrater agreement for each of the five personality traits. For extraversion, the lowest-scored job was "Bookkeeper" (3.00), and the highest-scored job was "Film, Stage, and Related Actor, Director" (6.67). For agreeableness, the lowest-scored job was "Armed Forces" (2.83), and the highest was "Religious Professional" 
(6.83). For conscientiousness, "Decorator, Commercial Designer" had the lowest score (5.17), and "Financial, Administration Department Manager" had the highest score (6.67). For emotional stability, "Building Structure Cleaner" had the lowest score (4.83), and "Fire Fighter" had the highest score (7.00). Finally, for openness, the lowest-scored job was "Government Tax and Excise Official" (3.17), and the highest-scored job was "Film, Stage, and Related Actor, Director" (7.00).

\section{Analytic strategy}

We used polynomial regression analysis and RSA (Shanock, Baran, Gentry, Pattison, \& Heggestad, 2010) to model the unique and joint influences of individuals' actual personality and job-demanded personality on income. (For accessible introductions to this method, see Schönbrodt, 2015; Edwards, 2002; and Barranti, Carlson, \& Côté, in press.) Advantages of RSA over traditional approaches included (a) the retention of variance both within and between job levels, (b) the retention of information about the levels of both personality- and job-related variables when determining the effect of personality-job fit, (c) the use of the entire range of values of the independent variables, and (d) the ability to model quadratic effects. The method has recently been used by a variety of authors to address research questions about personality-environment fit (e.g., Bleidorn et al., 2016; Boele, Sijtsema, Klimstra, Denissen, \& Meeus, in press; Franken, Laceulle, Van Aken, \& Ormel, 2017). Polynomial regression models were implemented in $\mathrm{R}$, using the lme4 package (Bates, Mächler, Bolker, \& Walker, 2014). Because both job personality demands (by definition) and individuals might be nested within jobs (e.g., because of selection processes), we controlled for job code (a unique integer assigned to each job) as a nesting variable in a multilevel model (note that this approach also excluded alternative explanations of results, such as the possibility that higher-paying jobs are simply likely to have better fit with jobholders' actual personalities).

Our RSA computed a response surface based on polynomial regression weights indicating the unique predictive effects of actual personality and job personality demands (linear and quadratic), as well as their interaction. Specifically, the following regression equations were estimated:

$$
\text { income }_{i j}=\beta_{1}+\beta_{2} \times \text { personality }_{i j}+\beta_{3} \times \text { personality }_{i j}{ }^{2}+\varepsilon_{i j}
$$

(Equation 1; Level 1)

$$
\beta_{1}=\gamma_{1}+\gamma_{2} \times \text { job demands }+\gamma_{3} \times \text { job demands }{ }^{2}+\mu_{1 j}
$$

(Equation 2; intercept)

$$
\beta_{2}=\gamma_{4}+\gamma_{5} \times \text { job demands }+\mu_{2 j}
$$

(Equation 3; linear slope for personality)

$$
\beta_{3}=\gamma_{6}+\mu_{3 j}
$$

(Equation 4; quadratic slope for personality)

These equations specified the income for person $i$ holding job $j$ as a function of that person's linear and quadratic personality scores and a residual term (Equation 1). The average income level was also allowed to vary as a function of linear and quadratic scores for job personality demands (Equation 2). Furthermore, the linear effect of personality was specified to interact with the level of job personality demands (when Equation 3 is plugged into Equation 1). Finally, random effects (i.e., between-job differences) were specified for the intercept as well as the linear and quadratic effects of personality traits (the $\mu$ parameters in Equations 2-4). From the resulting regression weights, we computed the four RSA coefficients using specialized equations that took into account the nested structure of the data (Shanock, Baran, Gentry, Pattison, \& Heggestad, 2014). These coefficients were then used to construct a threedimensional cube, with the two horizontal axes representing actual personality and job personality demands, respectively. The vertical axis represented the predicted income for different combinations of actual personality and job personality demands. We examined the data by relating the response surface of these predicted values to the two diagonals of the base: the line of congruence (LOC) and the line of incongruence (LOI):

- The LOC represented the diagonal on which actual and job-demanded personality were exactly congruent (e.g., the individual's actual level of extraversion was the same as the jobdemanded level of extraversion). If we found significant variation in income along the LOC, then we could investigate how different levels of congruent combinations of personality and job personality demands were related to income (e.g., was income higher when both actual personality and job personality demands were high on extraversion, as opposed to when both were low?). Both linear ( $a 1$ parameter) and quadratic (a2 parameter) effects were assessed.

- The LOI represented the other diagonal, on which actual and ideal jobholders' personalities were exactly opposite at the two poles of the continuum (e.g., the jobholder was high in extraversion, but the job demanded low extraversion, or vice versa). If we found significant variation in income along the LOI, then we could investigate which 


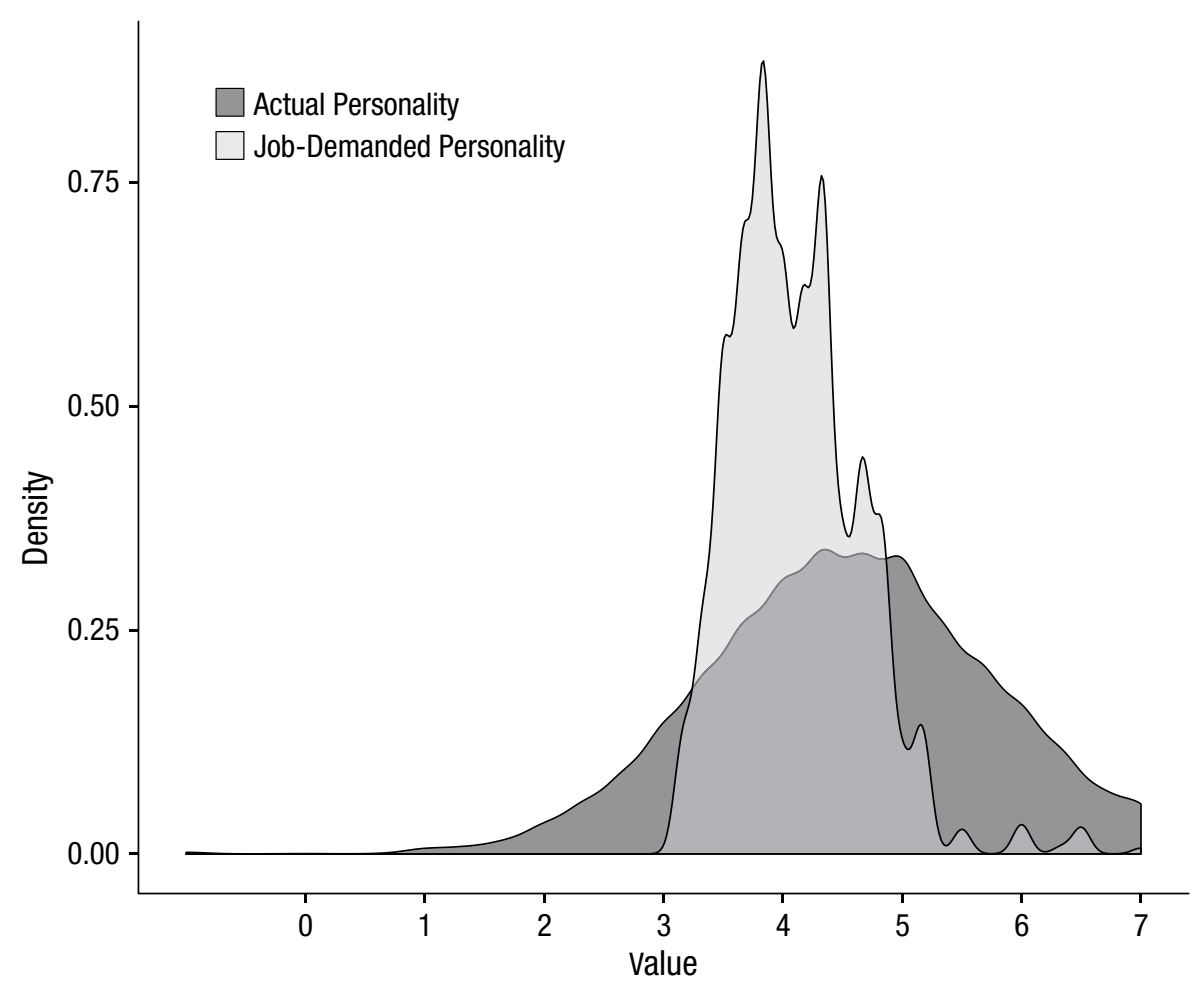

Fig. 1. Density distributions of actual and job-demanded openness to experience. Job demands and actual personality levels were assessed using the same metric, ranging from 1 (not at all true) to 7 (applies fully). Mostly overlapping distributions indicate that, theoretically, a large part of the population could achieve high congruence between their actual personality and the personality demands of their jobs.

kinds of incongruent combinations of personality and job personality demands were most beneficial or detrimental to income. The $a 3$ parameter assessed the linear effect of incongruence (e.g., whether it was beneficial specifically to have higher levels of a trait than the job demanded), and the a4 parameter assessed the curvilinear effect of incongruence (e.g., whether deviations between actual personality and job-demanded personality, regardless of direction, were associated with reduced income).

Note that our analytic framework was well suited to test the possibility of having "too much of a good thing" (Le et al., 2011), that is, a poor outcome when socially desirable traits reached overly high levels. Such an effect would be indicated by a positive linear regression coefficient ("a good thing"), coupled with a negative curvilinear coefficient ("too much"). (See Table S1 in the Supplemental Material for coefficients.) In the case of our RSA, "too much" was defined by referring to the job's demands (i.e., "too much for this particular job"). A "too much of a good thing" effect would be indicated by a negative $a 3$ or $a 4$ parameter.

\section{Results}

We generated bivariate density plots to examine the mean-level congruence between jobholders' actual personality traits and job personality demands (see Fig. 1 for the results for openness to experience and Figs. S1-S4 in the Supplemental Material for the results for the other traits). The five traits differed in their overlap (computed using the R package overlap; Meredith \& Ridout, 2016) between the distributions of actual personality traits and job personality demands. For openness to experience, the distributions overlapped $58 \%$; thus, at most, $58 \%$ of the population could find a job with job demands that exactly matched their level of openness. The overlap percentages were $73 \%$ for extraversion, $44 \%$ for agreeableness, $46 \%$ for conscientiousness, and 36\% for emotional stability. The somewhat lower overlap for emotional stability was due to levels of this personality trait lagging job demands. Average job-demanded emotional stability exceeded the average actual level of this trait, which suggests that emotional stability is a scarce psychological resource in the job context.

For every trait, at least one of the coefficients produced by the RSA (Edwards, 2002) was statistically 
Table 2. Response Surface Parameters Indicating Effects of Personality-Job Combinations on Annual Income

\begin{tabular}{|c|c|c|c|}
\hline Parameter & Coefficient & $\begin{array}{l}95 \% \text { confidence } \\
\text { interval }\end{array}$ & $p$ \\
\hline \multicolumn{4}{|c|}{ Extraversion } \\
\hline$a 1$ (linear effect of congruence) & 0.058 & {$[0.021,0.096]$} & .002 \\
\hline$a 2$ (curvilinear effect of congruence) & -0.009 & {$[-0.044,0.027]$} & .642 \\
\hline a3 (linear effect of incongruence) & -0.004 & {$[-0.041,0.034]$} & .855 \\
\hline$a 4$ (curvilinear effect of incongruence) & -0.031 & {$[-0.069,0.006]$} & .105 \\
\hline \multicolumn{4}{|c|}{ Agreeableness } \\
\hline$a 1$ (linear effect of congruence) & -0.008 & {$[-0.044,0.029]$} & .678 \\
\hline$a 2$ (curvilinear effect of congruence) & -0.017 & {$[-0.037,0.002]$} & .087 \\
\hline a3 (linear effect of incongruence) & -0.059 & {$[-0.096,-0.022]$} & .002 \\
\hline$a 4$ (curvilinear effect of incongruence) & -0.031 & {$[-0.054,-0.008]$} & .009 \\
\hline \multicolumn{4}{|c|}{ Conscientiousness } \\
\hline$a 1$ (linear effect of congruence) & 0.106 & {$[0.070,0.142]$} & $<.001$ \\
\hline$a 2$ (curvilinear effect of congruence) & 0.018 & {$[-0.009,0.046]$} & .194 \\
\hline a3 (linear effect of incongruence) & -0.102 & {$[-0.137,-0.066]$} & $<.001$ \\
\hline$a 4$ (curvilinear effect of incongruence) & -0.022 & {$[-0.049,0.005]$} & .117 \\
\hline \multicolumn{4}{|c|}{ Emotional stability } \\
\hline$a 1$ (linear effect of congruence) & 0.092 & {$[0.052,0.133]$} & $<.001$ \\
\hline$a 2$ (curvilinear effect of congruence) & 0.006 & {$[-0.024,0.037]$} & .687 \\
\hline$a 3$ (linear effect of incongruence) & -0.013 & {$[-0.054,0.028]$} & .534 \\
\hline$a 4$ (curvilinear effect of incongruence) & -0.019 & {$[-0.050,0.013]$} & .251 \\
\hline \multicolumn{4}{|c|}{ Openness to experience } \\
\hline$a 1$ (linear effect of congruence) & 0.057 & {$[0.018,0.096]$} & .004 \\
\hline$a 2$ (curvilinear effect of congruence) & -0.029 & {$[-0.047,-0.010]$} & .002 \\
\hline$a 3$ (linear effect of incongruence) & -0.054 & {$[-0.094,-0.014]$} & .009 \\
\hline$a 4$ (curvilinear effect of incongruence) & -0.038 & {$[-0.063,-0.014]$} & .002 \\
\hline
\end{tabular}

Note: The $a 1$ parameter (linear effect of the line of congruence) is positive when combinations of high traits and high job demands predict higher income levels. The $a 2$ parameter (curvilinear effect of congruence) is positive when there is an income bonus for individuals whose very low or very high levels of traits are congruent with their jobs' demands. The $a 3$ parameter (linear effect of the line of incongruence) is positive when income is higher if people's personality exceeds the level of job demands and negative when such combinations are associated with lower income. Finally, the $a 4$ parameter (curvilinear effect of incongruence) is positive when individual deviations from the normative job demands are rewarded with higher income and negative when such nonfitting combinations are associated with lower income.

significant (see Table 2). Results for the LOCs indicated that for all traits except agreeableness, congruent combinations of high levels of personality traits and high job personality demands were associated with higher incomes (positive $a 1$ coefficients) compared with congruent combinations of low levels of personality traits and low job personality demands. For openness, the effect was qualified by a curvilinear effect indicating diminishing returns at more extreme levels (negative $a 2$ coefficient). Results for the LOIs indicated that for agreeableness, conscientiousness, and openness, people whose trait levels exceeded the ideal trait levels earned less than people with congruent values of the trait (negative $a 3$ coefficients). Finally, the more jobholders' levels of agreeableness and openness deviated from the ideal levels of these traits in any direction, the less money they earned (negative $a 4$ coefficients).

Figure 2 shows the response surface of the personality-job interplay for openness to experience (see Figs. S5-S8 in the Supplemental Material for the response surfaces for the other traits). Combinations of low self-reported and low job-demanded openness (e.g., at the $-2,-2$ junction) were associated with low earnings, which is consistent with the positive $a 1$ and negative $a 2$ parameters for this trait. The LOI (i.e., the blue line running from left to right) indicates that there were benefits of a fit between actual personality and job personality demands. The curvature of the line 


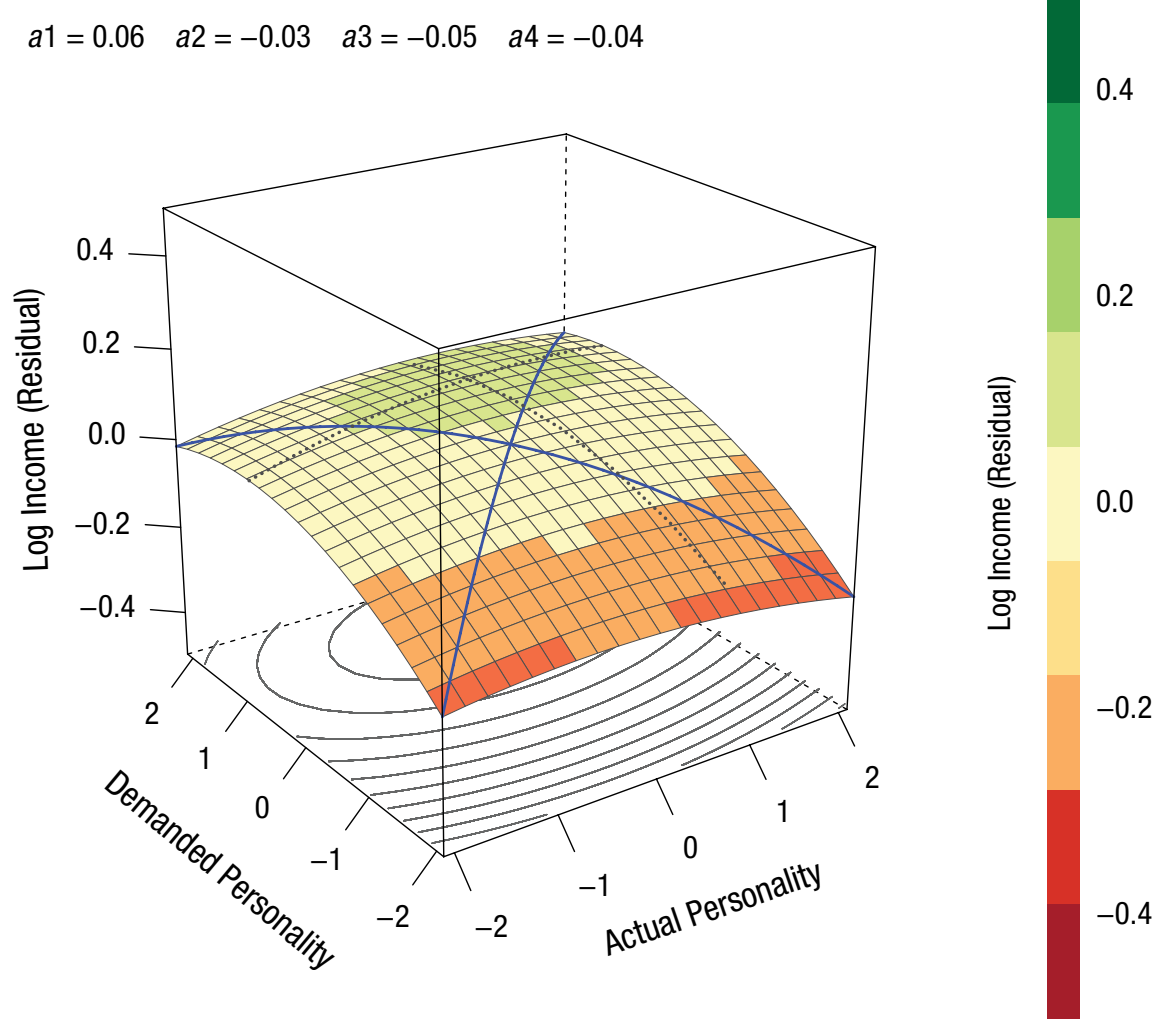

Fig. 2. Response surface indicating the association between income (vertical axis) and combinations of jobholders' actual openness to experience and their jobs' demands for openness to experience (the horizontal base). The shape of this response surface within this three-dimensional space is described by four statistical coefficients $(a 1-a 4)$, whose values are shown at the top of the graph. The colors on the surface correspond to log-transformed, residualized income values, as indicated on the color key to the right. The note to Table 2 explains how to interpret these coefficients. The blue lines running across the surface are the line of congruence (front to back) and the line of incongruence (left to right).

(negative a4 parameter) indicates that jobholders whose actual openness levels matched their jobs' ideal openness levels (center of the graph) earned the highest incomes. At points further from the center of the graph in any direction, income decreased. However, as the negative $a 3$ parameter indicates, the direction of discrepancy between individual personality and job personality demands also mattered. Income was lower at the rightmost part of the line than at the leftmost part of the line. This suggests that people whose actual openness was lower than demanded by their jobs were less affected by the mismatch between their own personality and their job's personality demands, compared with people whose openness levels exceeded their job's demands.

Traditional approaches to studying the effects of person-job fit rely on the computation of the differences between jobholders' characteristics and their jobs' characteristics, often after variables are dichotomized. Taking this approach in the current study resulted in results similar to those obtained in the RSA, demonstrating the robustness of our findings. For each of the five personality traits, Table 3 shows the difference in income between jobholders on either side of the LOI and those closer to the congruent midpoint of the LOI (i.e., fit bonus: income for the congruent group minus income for the incongruent groups combined). Specifically, for both job-demanded personality and actual personality, scores were categorized as "low" (L; lower than $1 S D$ below the average demanded or actual level), "medium" (M; from $1 S D$ below the average up to, but not including, $1 S D$ above the average), or "high" ( $\mathrm{H}$; equal to or higher than $1 S D$ above the average). These classifications were then used to create two noncongruent groups for each personality trait: one in which jobholders' actual level of the trait was low and the jobdemanded level was high (LH) and one in which jobholders' actual level of the trait was high and the job-demanded level was low (HL). A marginally significant fit effect was found for conscientiousness, but this 
Table 3. Comparison of Average (Adjusted) Annual Income (in Euros) for Different Levels of Fit Between Actual and Job-Demanded Personality

\begin{tabular}{lccccc}
\hline & \multicolumn{5}{c}{$\begin{array}{c}\text { Combination of actual and } \\
\text { job-demanded personality }\end{array}$} \\
\cline { 2 - 5 } Trait & LH & $\begin{array}{c}\text { MM } \\
\text { (congruent) }\end{array}$ & HL & $\begin{array}{c}\text { LH and HL mean } \\
\text { (incongruent) }\end{array}$ & $\begin{array}{c}\text { Fit bonus } \\
\text { (congruent - } \\
\text { incongruent) }\end{array}$ \\
\hline Extraversion & 37,064 & 39,314 & 37,182 & 37,123 & 2,191 \\
Agreeableness & 37,098 & 39,150 & 33,330 & 35,214 & 3,935 \\
Conscientiousness & 39,373 & 36,566 & 34,035 & 36,704 & -138 \\
Emotional stability & 37,180 & 37,574 & 34,878 & 36,029 & - \\
Openness & 35,513 & 38,919 & 35,863 & 35,688 & 3,231 \\
\hline
\end{tabular}

Note: Income levels were adjusted for covariates but were not log-transformed. For both job-demanded personality and actual personality, scores were categorized as "low" (L; lower than $1 S D$ below the average demanded or actual level), "medium" (M; from $1 S D$ below the average up to, but not including, $1 S D$ above the average), or "high" (equal to or higher than $1 S D$ above the average). These classifications were then used to create two noncongruent groups for each personality trait: one in which jobholders' actual level of the trait was low and the job-demanded level was high (LH) and one in which jobholders' actual level of the trait was high and the job-demanded level was low (HL). The labels for the groups indicate the categorization of the jobholder and then the categorization of the job; for example, "LH" refers to individuals who had low levels of the indicated trait and jobs that demanded high levels of that trait. The fit bonus is reported only for those traits that had at least a marginally significant $a 4$ parameter $(p<.12)$.

effect was washed out by a strong main effect of job demands; as shown in Table 3, the fit bonus for the LH group was negative. In contrast, the average annual income of the congruent (MM) group was greater than the average annual income of the incongruent (LH and $\mathrm{HL})$ groups for extraversion $(€ 2,191)$, agreeableness $(€ 3,935)$, and openness to experience $(€ 3,231)$. A fit bonus was not calculated for emotional stability because the a4 parameter did not reach the level of marginal significance.

\section{Discussion}

In summary, the interplay between actual and jobdemanded trait levels had an impact on income. Personality traits should be predictive of earnings because they correlate with the efficiency of mastering jobrelated tasks (Hoffman \& Woehr, 2006). In addition, we expected that personality traits would interact with job demands to predict income (as suggested by Judge \& Zapata, 2015). In the most striking instance of such an interaction, we found that it can be disadvantageous to have trait levels higher than the levels a job demands (even if these traits are generally viewed as favorable). For example, highly conscientious individuals whose jobs did not demand such levels actually had lower earnings than individuals who were low in conscientiousness and had jobs that demanded high levels, a finding that deviates from the often-reported positive association between conscientiousness and earnings
(Barrick \& Mount, 1991; Fletcher, 2013; Nyhus \& Pons, 2005).

Two major conclusions stand out. First, in the case of extraversion, agreeableness, and openness to experience, congruence between actual personality and job demands was predictive of substantially higher income (i.e., fit bonus). For these traits, the distributions of actual personality and job demands also overlapped substantially. Furthermore, for these traits, the average jobholder's actual personality correlated most strongly and positively with expert-rated personality demands (see Table S3 in the Supplemental Material). This finding can be explained by two mechanisms. To begin, people might themselves select jobs or be selected for jobs that match their actual personalities (Roberts, Caspi, \& Moffitt, 2003). It should be noted, however, that this assortative mechanism is limited to the extent that it is probably not feasible to select jobs that match all one's traits, so selection most likely takes place on salient characteristics only. Furthermore, people's actual personality might change over time toward levels demanded by their jobs (Denissen, Ulferts, Lüdtke, Muck, \& Gerstorf, 2014).

Second, for emotional stability and, to a lesser extent, conscientiousness, job personality demands were on average higher than people's actual personality levels (see Figs. S3 and S4 in the Supplemental Material). That is, many people are not conscientious and emotionally stable enough to fully satisfy the demands of their jobs. This should shape labor-market dynamics according to 
scarcity principles (i.e., personality traits for which the supply is lower than the demand should receive additional gratification). Consistent with this reasoning is our finding that the "human capital" of high conscientiousness and emotional stability was generously rewarded in jobs with high demands for these traits, as indicated by the strongly positive $a 1$ parameters. The most plausible explanation of this effect is that the actual performance of highly conscientious and emotionally stable people in vocational niches that demand high levels of these traits is superior to that of people who cannot live up to these demands and is therefore rewarded with higher pay (Hoffman \& Woehr, 2006).

A correlational analysis reported in the Supplemental Material (Table S4) offers novel perspectives on labormarket dynamics, showing that the predictive validity of average levels of personality traits (aggregated across jobholders) can be distinct from the predictive validity of job-demanded personality traits. For example, the average level of jobholders' conscientiousness was negatively associated with earnings, whereas the average level of job-demanded conscientiousness was positively associated with earnings. Thus, both the individual and the combined effects of individual traits and personality-relevant job demands need to be taken into account to fully understand transactions between persons and job environments.

\section{Limitations and future research}

This study had some limitations, which should be addressed by future studies. First, even though we used a fine-grained four-digit system for coding jobs and had independent raters code jobs with respect to their Big Five demands, the job categories (e.g., "Armed Forces") might still be considered relatively general. Future research is needed to explore finer distinctions among occupational categories (e.g., different ranks within the armed forces), and possibly to distinguish job demands that are unique to specific organizations or units (e.g., air force, marines). Future studies should therefore compare experts' ratings of the role demands of different status levels with participants' self-rated personality to see whether congruent combinations, compared with incongruent combinations, are associated with higher incomes. Another possible nuance could be added by letting raters evaluate the minimum and maximum levels of personality traits that are associated with optimal job performance. In addition, even though the overall reliability of our experts' ratings was satisfactory, the reliability of some of the ratings (e.g., for conscientiousness) could be improved, perhaps by making the descriptors for the traits more specific (e.g., by clarifying what it means to "do a thorough job"), so as to counteract range restriction due to floor or ceiling effects. Finally, our ratings pertain to a specific geographic region (Germany) and historical period (20052009). It is possible that they do not generalize to other regions or times.

Another issue for future research concerns the proximal mechanisms of fit effects. For example, studies could test whether job performance or job satisfaction mediates the observed effects of person-job fit on income. Another possible mechanism could be stereotype congruence effects. Specifically, it might be that effects of person-job fit on income result partly from the fact that jobholders who better fit the stereotype of a certain profession (e.g., being a typical "military man") earn more in their profession. This might be the case, for example, because they are more easily considered for job promotions. Finally, personality dimensions might work in tandem; that is, they could show synergistic or compensatory effects in the prediction of income. A first step in addressing this possibility would be to derive personality types that consist of combinations of traits and then investigating if having a personality type that fits one's job is associated with higher earnings.

\section{Conclusion}

Our findings call for a more nuanced theoretical perspective on personality traits in investigations of the effects of person-environment fit. They indicate that the adaptive consequences of traits depend on the context in which they are deployed, such as the job personality demands associated with one's vocation. This context dependence nicely dovetails with the established importance, supported by a recent meta-analysis (Nye, Su, Rounds, \& Drasgow, 2012), of fit, or congruence, in the vocational psychological literature. Our study provides a rationale for current economic practices such as finding a job that fits one's personality traits (for job seekers) and hiring individuals with appropriate personality traits (for employers). Given the size of the observed effects, individuals might find it beneficial to employ ambitious strategies for obtaining fit, such as changing their traits (i.e., self-improvement via intentional personality change; Hennecke, Bleidorn, Denissen, \& Wood, 2014), a process constrained by stability factors (Boyce, Wood, \& Powdthavee, 2012; Fraley \& Roberts, 2005), or changing the nature of the job they hold (Berg, Wrzesniewski, \& Dutton, 2010). Given the clear economic value of fit, it would also be beneficial for labor-market policies to focus more on fit rather than just personality traits.

\section{Action Editor}

Brent W. Roberts served as action editor for this article. 


\section{Author Contributions}

J. J. A. Denissen came up with the idea for the study, coordinated the process of obtaining the job ratings, and processed the data. All the authors engaged in conceptual discussions and refinement of the study idea. J. J. A. Denissen performed the statistical analyses, aided by M. Hennecke, M. Luhmann, and J. Zimmermann. J. J. A. Denissen drafted the manuscript, and all the other authors provided critical revisions. All the authors approved the final version of the manuscript for submission. Except for the first author, all the authors contributed equally to this manuscript.

\section{Acknowledgments}

We thank Juliane Hennecke and Sigi Lindenberg for valuable comments on earlier versions of this manuscript. We also thank Markus Held, Nicolas Sander, and Stefan Schiffer for providing the ratings of job-demanded personality.

\section{Declaration of Conflicting Interests}

The authors declared that they had no conflicts of interest with respect to their authorship or the publication of this article.

\section{Funding}

This research was supported by Grant SP 1462/1-1 (Scientific Network on Adult Personality Development) from the German Research Foundation to J. Specht.

\section{Supplemental Material}

Additional supporting information can be found at http:// journals.sagepub.com/doi/suppl/10.1177/0956797617724435

\section{Open Practices

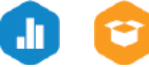

All data and materials have been made publicly available via the German Socio-Economic Panel (SOEP; https://www.diw.de/ en/soep) and via the Open Science Framework at https://osf .io/9v34x. The questionnaires and other materials from the SOEP can be accessed at https://www.diw.de/en/diw_02.c.239921.en/ codebooks.html and http://zis.gesis.org/skala/Schupp-GerlitzBig-Five-Inventory-SOEP-(BFI-S). The complete Open Practices Disclosure for this article can be found at http://journals.sagepub .com/doi/suppl/10.1177/0956797617724435. This article has received badges for Open Data and Open Materials. More information about the Open Practices badges can be found at http:// www.psychologicalscience.org/publications/badges.

\section{Note}

1. Note that the expert ratings used in this study differed from the ratings that were used in a previous publication (Denissen, Ulferts, Lüdtke, Muck, \& Gerstorf, 2014), which focused on job personality demands as a predictor of personality change. In this earlier publication, experts from the Federal Employment Agency provided consensus ratings on a scale from 0 to 2 . The two sets of ratings correlated from .48 (conscientiousness) to .75 (openness to experience).

\section{References}

Barranti, M., Carlson, E. N., \& Côté, S. (in press). How to test questions about similarity in personality and social psychology research: Description and empirical demonstration of response surface analysis. Social Psychological E Personality Science.

Barrick, M. R., \& Mount, M. K. (1991). The Big Five personality dimensions and job performance: A meta-analysis. Personnel Psychology, 44, 1-26. doi:10.1111/j.1744-6570.1991.tb00688 $\mathrm{x}$

Barrick, M. R., Mount, M. K., \& Li, N. (2013). The theory of purposeful work behavior: The role of personality, higher-order goals, and job characteristics. Academy of Management Review, 38, 132-153. doi:10.5465/amr .2010 .0479

Bates, D., Mächler, M., Bolker, B., \& Walker, S. (2014). Fitting linear mixed-effects models using lme4. Retrieved from http://arxiv.org/abs/1406.5823

Berg, J. M., Wrzesniewski, A., \& Dutton, J. E. (2010). Perceiving and responding to challenges in job crafting at different ranks: When proactivity requires adaptivity. Journal of Organizational Behavior, 31, 158-186. doi:10.1002/ job. 645

Bleidorn, W., Schönbrodt, F., Gebauer, J. E., Rentfrow, P. J., Potter, J., \& Gosling, S. D. (2016). To live among likeminded others: Exploring the links between person-city personality fit and self-esteem. Psychological Science, 27, 419-427.

Boele, S., Sijtsema, J. J., Klimstra, T. A., Denissen, J. J. A., \& Meeus, W. H. J. (in press). Misfits in adolescence? Persongroup dissimilarity in personality and peer victimization. European Journal of Personality.

Borghans, L., Duckworth, A. L., Heckman, J. J., \& ter Weel, B. (2008). The economics and psychology of personality traits. Journal of Human Resources, 43, 972-1059. doi:10.3368/jhr.43.4.972

Bowles, S., Gintis, H., \& Osborne, M. (2001). Incentiveenhancing preferences: Personality, behavior, and earnings. American Economic Review, 91, 155-158.

Boyce, C. J., Wood, A. M., \& Powdthavee, N. (2012). Is personality fixed? Personality changes as much as "variable" economic factors and more strongly predicts changes to life satisfaction. Social Indicators Research, 111, 287-305. doi:10.1007/s11205-012-0006-Z

Denissen, J. J. A., Ulferts, H., Lüdtke, O., Muck, P. M., \& Gerstorf, D. (2014). Longitudinal transactions between personality and occupational roles: A large and heterogeneous study of job beginners, stayers, and changers. Developmental Psychology, 50, 1931-1942. doi:10.1037/ a0036994

Edwards, J. R. (2002). Alternatives to difference scores: Polynomial regression analysis and response surface methodology. In F. Drasgow \& N. Schmitt (Eds.), Measuring and analyzing behavior in organizations: Advances in measurement and data analysis (pp. 350400). San Francisco, CA: Jossey-Bass.

Fletcher, J. M. (2013). The effects of personality traits on adult labor market outcomes: Evidence from siblings. Journal of Economic Behavior \& Organization, 89, 122135. doi:10.1016/j.jebo.2013.02.004 
Fraley, C. R., \& Roberts, B. W. (2005). Patterns of continuity: A dynamic model for conceptualizing the stability of individual differences in psychological constructs across the life course. Psychological Review, 112, 60-74. doi:10.1037/0033-295X.112.1.60

Franken, A., Laceulle, O. M., Van Aken, M. A. G., \& Ormel, J. (2017). Using response surface analysis to interpret the impact of parent-offspring personality similarity on adolescent externalizing problems. European Journal of Personality, 31, 104-117.

Gerlitz, J.-Y., \& Schupp, J. (2005). Zur Erhebung der Big-Fivebasierten Persönlichkeitsmerkmale im SOEP [Assessment of Big-Five-based personality traits in the SOEP]. Berlin, Germany: Deutsches Institut für Wirtschaftsforschung.

Groves, M. O. (2005). How important is your personality? Labor market returns to personality for women in the US and UK. Journal of Economic Psychology, 26, 827-841. doi:10.1016/j.joep.2005.03.001

Hahn, E., Gottschling, J., \& Spinath, F. M. (2012). Short measurements of personality: Validity and reliability of the GSOEP Big Five Inventory (BFI-S). Journal of Research in Personality, 46, 355-359.

Hennecke, M., Bleidorn, W., Denissen, J. J. A., \& Wood, D. (2014). A three-part framework for self-regulated personality development across adulthood. European Journal of Personality, 28, 289-299. doi:10.1002/per.1945

Hoffman, B. J., \& Woehr, D. J. (2006). A quantitative review of the relationship between person-organization fit and behavioral outcomes. Journal of Vocational Behavior, 68, 389-399. doi:10.1016/j.jvb.2005.08.003

John, O. P., \& Srivastava, S. (1999). The Big-Five trait taxonomy: History, measurement, and theoretical perspectives. In L. A. Pervin \& O. P. John (Eds.), Handbook of personality: Theory and research (Vol. 2, pp. 102-138). New York, NY: Guilford Press.

Judge, T. A., Higgins, C. A., Thoresen, C. J., \& Barrick, M. R. (1999). The Big Five personality traits, general mental ability, and career success across the life span. Personnel Psychology, 52, 621-652.

Judge, T. A., \& Zapata, C. P. (2015). The person-situation debate revisited: Effect of situation strength and trait activation on the validity of the Big Five personality traits in predicting job performance. Academy of Management Journal, 58, 1149-1179.

Le, H., Oh, I.-S., Robbins, S. B., Ilies, R., Holland, E., \& Westrick, P. (2011). Too much of a good thing: Curvilinear relationships between personality traits and job performance. Journal of Applied Psychology, 96, 113-133.

Meredith, M., \& Ridout, M. (2016). overlap: Estimates of coefficient of overlapping for animal activity patterns (Version 0.3.0) [Computer software]. Retrieved from http://CRAN.Rproject.org/package $=$ overlap
Mueller, G., \& Plug, E. (2006). Estimating the effect of personality on male and female earnings. Industrial and Labor Relations Review, 60, 3-22.

Nye, C. D., Su, R., Rounds, J., \& Drasgow, F. (2012). Vocational interests and performance: A quantitative summary of over 60 years of research. Perspectives on Psychological Science, 7, 384-403.

Nyhus, E., \& Pons, E. (2005). The effects of personality on earnings. Journal of Economic Psychology, 26, 363-384.

Roberts, B. W., Caspi, A., \& Moffitt, T. E. (2003). Work experiences and personality development in young adulthood. Journal of Personality and Social Psychology, 84, 582-593.

Roberts, B. W., Kuncel, N. R., Shiner, R., Caspi, A., \& Goldberg, L. R. (2007). The power of personality: The comparative validity of personality traits, socioeconomic status, and cognitive ability for predicting important life outcomes. Perspectives on Psychological Science, 2, 313345. doi:10.1111/j.1745-6916.2007.00047.x

Roberts, B. W., \& Robins, R. W. (2004). Person-environment fit and its implications for personality development: A longitudinal study. Journal of Personality, 72, 89-110.

Schönbrodt, F. D. (2015). Testing fit patterns with polynomial regression models. Manuscript submitted for publication.

Shanock, L. R., Baran, B. E., Gentry, W. A., Pattison, S. C., \& Heggestad, E. D. (2010). Polynomial regression with response surface analysis: A powerful approach for examining moderation and overcoming limitations of difference scores. Journal of Business and Psychology, 25, 543-554. doi:10.1007/s10869-010-9183-4

Shanock, L. R., Baran, B. E., Gentry, W. A., Pattison, S. C., \& Heggestad, E. D. (2014). Erratum to: Polynomial regression with response surface analysis: A powerful approach for examining moderation and overcoming limitations of difference scores. Journal of Business and Psychology, 29, 161. doi:10.1007/s10869-013-9317-6

Spokane, A. R., Meir, E. I., \& Catalano, M. (2000). Personenvironment congruence and Holland's theory: A review and reconsideration. Journal of Vocational Behavior, 57, 137-187.

Tinsley, H. E. A. (2000). The congruence myth: An analysis of the efficacy of the person-environment fit model. Journal of Vocational Behavior, 56, 147-179. doi:10.1006/ jvbe.1999.1727

Wagner, G. G., Frick, J. R., \& Schupp, J. (2007). The German Socio-Economic Panel Study (SOEP) - Evolution, scope and enhancements (SSRN Scholarly Paper No. 1028709). Retrieved from http://papers.ssrn.com/abstract=1028709

Wolf, C. (1997). The ISCO-88 International Standard Classification of Occupations in Cross-National Survey Research. Bulletin of Sociological Methodology/Bulletin de Méthodologie Sociologique, 54(1), 23-40. doi:10.1177/ 075910639705400102 